\title{
Cellular origin of pro-coagulant and (anti)- fibrinolytic factors in bleomycin-injured lungs
}

\author{
M. Wygrecka*, , P. Markart ${ }^{\#, \oplus, ~ C . ~ R u p p e r t " ~}{ }^{\#}$, K. Petri ${ }^{\#}$, K.T. Preissner*, \\ W. Seeger ${ }^{\#}$ and A. Guenther ${ }^{\#}$
}

ABSTRACT: Excessive pro-coagulant and decreased fibrinolytic activities in the alveolar compartment have been repeatedly documented for inflammatory and fibrotic lung diseases. The current authors determined the contribution of different resident lung cells to the altered local production of coagulation- and fibrinolysis-system components in bleomycin-injured mouse lungs via cell-specific and quantitative assessment of mRNA levels of various pro-coagulant and (anti)fibrinolytic factors.

Laser-assisted microdissection technology was used to sample specific cell populations in combination with subsequent mRNA analysis by real-time quantitative reverse transcriptase-PCR. Additionally, western blot analysis, immunohistochemistry and activity assays were performed.

Following bleomycin challenge, the strongest induction of tissue factor and plasminogen activator inhibitor (PAI)-1 mRNA expression was observed in alveolar macrophages ( $250-$ and 60-fold induction, respectively). These factors were also upregulated in alveolar type II cells, but to an approximately six-fold lesser extent. In contrast, PAI-2 expression was induced exclusively in alveolar macrophages. A slight increase of urokinase-type plasminogen activator (UPA) expression was also observed in alveolar macrophages (two-fold induction), but uPA activity was reduced due to a disproportionate increase of PAl production.

Alveolar macrophages and, to a lesser extent, alveolar type II cells are the main sources of locally produced pro-coagulant and anti-fibrinolytic factors in bleomycin-injured lungs.

KEYWORDS: Acute lung injury/acute respiratory distress syndrome, alveolar macrophage, alveolar type II cell, gene expression and regulation, haemostasis, pulmonary fibrosis

xcessive pro-coagulant and decreased fibrinolytic activities are commonly observed in the lungs of patients with acute inflammatory lung diseases, such as acute respiratory distress syndrome, and with fibrotic lung diseases, such as idiopathic pulmonary fibrosis [1, 2]. Similar alterations have been reported in animal models of acute lung injury and pulmonary fibrosis, including that of bleomycin-induced lung injury [3, 4]. Increase of pro-coagulant activity in the alveolar space in these conditions is mainly attributable to tissue factor (TF)-induced activation of the coagulation cascade [1-4]. TF initiates the extrinsic coagulation pathway by binding and activating coagulation factor VII. The resulting TF-VIIa complexes bind and activate factor $X$, which triggers the generation of thrombin that converts soluble fibrinogen to insoluble fibrin [5]. Intra-alveolar depression of fibrinolytic activity in the acutely and chronically injured lung is, in large, attributable to plasminogen activator inhibitor (PAI)-1 [1-4]. TF-VIIa complexes and elevated levels of factor $\mathrm{Xa}$, thrombin and PAI-1 are commonly found in bronchoalveolar lavage fluid (BALF) obtained from patients with acute inflammatory and fibrotic lung diseases and also in bleomycin-injured lungs [1-3, 6, 7]. Additionally, intra-alveolar accumulation of fibrin is commonly observed in these disorders [1-4]. Fibrin is thought to promote the fibrotic response by providing a provisional matrix for fibroblast proliferation and activation [8]. In addition to its pro-coagulant effects, coagulation proteases, such as thrombin and factor $\mathrm{Xa}$, exert various cellular effects that may also contribute to inflammation and fibrosis following tissue injury [9-14].

Imbalances in alveolar haemostasis and fibrinolysis and intra-alveolar fibrin accumulation in the acutely and chronically injured lung are thought to arise from a leakage of plasma and its coagulation substrates into the alveolar compartment. In turn, this is due to disturbed integrity of the capillary alveolar barrier in combination with altered local production of pro- and anti-coagulant
AFFILIATIONS

Depts of *Biochemistry, and

* Internal Medicine, Faculty of

Medicine, University of Giessen Lung

Center, Giessen, Germany.

"Both authors contributed equally to the manuscript.

CORRESPONDENCE

P. Markart

Dept of Internal Medicine

University of Giessen Lung Center

Klinikstr. 36

35392 Giessen

Germany

Fax: 496419942429

E-mail: philipp.markart@innere.med.

uni-giessen.de

Received:

July 252006

Accepted after revision:

February 122007

STATEMENT OF INTEREST

None declared. 
and (anti)-fibrinolytic factors by resident lung cells, which is induced by tissue injury and inflammatory cytokines [1, 3, 15]. Accordingly, it was recently demonstrated that the alveolar compartment itself is an important source of pro-coagulant and anti-fibrinolytic activity in the acutely inflamed lung [15]. However, little is known about the contribution of different lung cells to the local production of pro-coagulant and (anti)fibrinolytic factors in these conditions. Early reports identified alveolar macrophages (AM) as a potential source of TF and PAI$1[16,17]$, but some in vitro and in vivo studies suggest that lung epithelial cells may also contribute to the pronounced changes in the alveolar haemostatic balance under inflammatory conditions $[4,15,18,19]$. TF is also expressed by fibroblasts and endothelial cells (EC) [20, 21]. Therefore, several resident lung cells could contribute to the altered alveolar haemostasis in inflammatory and fibrotic lung diseases.

In this context, the objective of the present study was the cellspecific and quantitative assessment of mRNA levels of key factors of the coagulation (TF and TF pathway inhibitor (TFPI)) and fibrinolysis (urokinase-type and tissue-type plasminogen activators (uPA and tPA, respectively), PAI-1, PAI-2) systems in bleomycin-injured mouse lungs. In the present study, a recently developed laser-assisted cell-picking technique [15, 22] was applied to the bleomycin model of pulmonary fibrosis for the first time, in order to collect various cell populations from the alveolar compartment; this method was used in combination with subsequent mRNA analysis by real-time quantitative reverse transcriptase (RT)-PCR.

\section{METHODS}

\section{Bleomycin administration}

Animal experimentation was performed according to the Helsinki convention for the use and care of animals and was approved by the Justus-Liebig-University's Committee on Animal Investigations (Giessen, Germany). Six-week-old Balb/c mice were anaesthetised, orotracheally intubated and mechanically ventilated. Bleomycin (Almirall Prodesfarma, Barcelona, Spain; $15 \mathrm{mg} \cdot \mathrm{kg}^{-1}$ in $200 \mu \mathrm{L}$ of a $0.9 \%$ sodium chloride solution) was administered as an aerosol via a microsprayer (Penn-Century Inc., Philadelphia, PA, USA). Age- and sex-matched controls received $0.9 \%$ sodium chloride solution only. Groups of 10 mice were killed by i.p. injection of a lethal dose of ketamine and xylazine at 4 and 28 days after bleomycin administration.

\section{Pulmonary compliance}

Mice were tracheotomised and ventilated in a volume driven mode at a positive end-expiratory pressure of $0 \mathrm{kPa}$. Respiration rate was set at 20 breaths $\cdot \mathrm{min}^{-1}$ and ventilation pressure was recorded while inflating the lung at a tidal volume of $200 \mu \mathrm{L}$. Ventilator compliance is given and was corrected for the animal weight.

\section{Bronchoalveolar lavage procedure and lung preparation}

Details of the procedure are provided elsewhere [15]. BALF macrophages were purified by adherence to plastic tissueculture dishes for $60 \mathrm{~min}$ at $37^{\circ} \mathrm{C}$. For RNA analysis, purified BALF macrophages were resuspended in $300 \mu \mathrm{L}$ guanidine thiocyanate (GTC) buffer (4 M GTC, $25 \mathrm{mM}$ tribasic sodium citrate, $100 \mathrm{mM}$ TRIS; pH 7.5, containing $0.5 \%$ N-lauroylsarcosine, and $0.8 \% \quad \beta$-mercaptoethanol). For western blot analysis, BALF macrophages were resuspended in ice-cold lysis buffer (20 mM TRIS, $150 \mathrm{mM}$ sodium chloride, $1 \mathrm{mM}$ EDTA, $1 \mathrm{mM}$ EGTA, 1\% Triton X-100, $2.5 \mu \mathrm{M}$ sodium pyrophosphate, $1 \mathrm{mM} \quad \beta$-glycerophosphate, $1 \mathrm{mM}$ sodium orthovanadate, $1 \mathrm{mM}$ phenylmethyl suphonyl fluoride; $\mathrm{pH} 7.5,1 \mu \mathrm{g} \cdot \mathrm{mL}^{-1}$ complete).

\section{Microdissection of lung cells}

Lung cells (AM, smooth muscle cells (SMC) and EC of medium-size pulmonary vessels, and alveolar type II cells (ATII)) were laser-microdissected from snap-frozen lungs after instillation of Tissue-Tek ${ }_{\circledR}$ (Sakura Finetek, Zoeterwoude, the Netherlands) as recently described [15, 22]. Briefly, for microdissection of $\mathrm{AM}$ and SMC, cryostat sections were stained with haemalaun. AM and SMC were identified by their shape and localisation, and were laser-microdissected under visual control (PALM, Bernried, Germany). For the identification of ATII and EC, sections were stained immunohistochemically with a rabbit anti-pro-surfactant protein (SP)-C antibody (Chemicon, Temecula, CA, USA) and a rabbit antivon Willebrand Factor (vWF)-antibody (Dako, Glostrup, Denmark), respectively. ATII and EC were selected according to their staining pattern and laser-microdissected under visual control.

\section{Isolation of total cellular RNA and RT reaction}

RNA was extracted from lung homogenate, BALF macrophages and microdissected SMC using phenol/chloroform [23], precipitated with isopropanol, and dissolved in RNasefree water. In view of the overall low abundance of cellular material, RNA isolation was not performed in any of the other microdissected cell types. For details on the RT reaction see [15].

\section{Relative mRNA quantification using TaqMan ${ }^{\text {TM }}$ PCR}

Primers and TaqMan ${ }^{\mathrm{TM}}$ probes (Metabion, Martinsried, Germany) were designed with the computer program Primer Express (Software Version 2.0; Applied Biosystem, Foster City, CA, USA). TF: forward, 5'-GGGTTGCCACTCCAAAATTGT-3'; reverse, 5'-CGTTTCTCGGCTGCCTCC-3'. Probe: 5'-ACCGCGGGTGCAGGCATTCC-3'. TFPI: forward, 5'-AGTGTAAGAAAACATGCATACCAGGTT-3'; reverse, 5'-CTCGGCAGAGTCCAGGGT-3'. Probe: 5'-AGAAATCTGGCCTTTCTGCTCCAGATGCT-3'. PAI-1: forward, 5'-AGGTCAGGATCGAGGTAAACGAG-3'; reverse, 5'-GGATCGGTCTATAACCATCTCCGT-3'. Probe: 5'-TCTTCCTCCACAGCCTTTGTCATCTCAGC-3'. PAI-2: forward, 5'-ATCT-CATCAACATTGGCCATAGTTC-3'; reverse, 5'-TGGGTTTCTTGTGGTGATACCATA-3'. Probe: 5'-TAAACTGCAGCACTTTGGCCACTCGCT-3'. uPA: forward, 5'-TCAGAAACC-CTACAATGCCCA3'; reverse, 5'-CACATAGCACCAGGGTCGCT-3'. Probe: 5'CACAATTACTGCAGGAACCCTGACAACCA-3'. tPA: forward, 5'-CAACAGCGGCCT-GGTACAAT-3'; reverse, 5'TACAGGGCCTGCTGACACGT-3'. Probe: 5'-TGCCTGTCCGAAGTTGCAGCGAAC-3'. $\beta$-Actin: forward, 5'-AGAGGGAAATCGTGCGTGAC-3'; reverse, 5'-CAATAGTGATGACCTGGCCGT-3'. Probe: 5'-CACTGCCGCATCCTCTTCCTCCC-3'.

Details on the TaqMan ${ }^{\mathrm{TM}}$ PCR are outlined elsewhere [15]. The $\mathrm{n}$-fold change in target gene relative to the endogenous control $\beta$-actin was determined by: 


$$
\mathrm{n} \text {-fold change in target gene }=2^{-\Delta \Delta C t}
$$

where $\Delta \Delta \mathrm{Ct}_{\mathrm{t}}=(\mathrm{C} \mathrm{t}$,target $-\mathrm{Ct}$,actin $)$ bleomycin treated $-(\mathrm{Ct}$,target $-\mathrm{Ct}$,actin $)$ control and $\mathrm{Ct}$ : threshold cycle.

Relative quantification of gene expression using the $2^{-\Delta \Delta C}$ method correlated with the absolute gene quantification obtained using standard curves.

\section{Western blot analysis}

Western blot analysis on cell-free BALF supernatants $\left(25 \mu \mathrm{L} \cdot\right.$ lane $\left.^{-1}\right)$, lung homogenates $\left(10 \mu \mathrm{g}\right.$ protein $\cdot$ lane $\left.^{-1}\right)$ and BALF macrophage cell lysates $\left(10 \mu \mathrm{g}\right.$ protein $\cdot$ lane $\left.^{-1}\right)$ was performed using a rabbit anti-PAI-1, goat anti-PAI-2 (both Santa Cruz Biotechnology, Santa Cruz, CA, USA) or rabbit anti-TF (American Diagnostica, Greenwich, CT, USA) antibody, and horseradish-peroxidase-labelled secondary antibody (Dako). Final detection of protein was performed using enhanced chemiluminescence (Pierce, Rockford, IL, USA). In the case of BALF macrophages and lung homogenate, membranes were stripped $(2 \%$ sodium dodecyl sulphate (SDS), $100 \mathrm{mM} \beta$-mercaptoethanol in TBS), and re-probed with mouse anti- $\beta$-actin antibody (Sigma-Aldrich, Taufkirchen, Germany).

\section{Immunohistochemistry}

Lung tissue specimens were fixed with $4 \%$ formaldehyde in PBS and embedded in paraffin. Five- $\mu \mathrm{m}$ sections were deparaffinised in xylene and rehydrated through graded ethanol washes. Immunohistochemistry was performed using Histostain-Plus Kit (Zymed Laboratories Inc., San Francisco, CA, USA) with the same primary antibodies as for western blot analyses. For safe and reliable identification of positive cells, immunohistochemical staining was performed on serial sections by the use of antibodies recognising vWF (EC), pro-SP-C (ATII), and CD68 (macrophages). Controls were performed by substituting the primary antibody for a nonspecific antibody.

\section{Casein zymography}

BALF $\left(5 \mu \mathrm{L} \cdot\right.$ lane $\left.^{-1}\right)$ and lung homogenate $\left(5 \mu \mathrm{g}\right.$ protein $\cdot$ lane $\left.^{-1}\right)$ were subjected to electrophoresis on $10 \%$ SDS polyacrylamide gels under nonreducing conditions. Following electrophoresis, the gel was washed twice for 10 min with $2.5 \%$ Triton X-100 in water, and then twice for $10 \mathrm{~min}$ with PBS. Subsequently, the polyacrylamide gel was overlaid on plasminogen/substrate gels composed of $2.5 \%$ agarose, $2 \%$ nonfat dry milk and $40 \mu \mathrm{g} \cdot \mathrm{mL}^{-1}$ plasminogen. The gel-underlay complex was placed in a sealed, humidified container, incubated overnight at $4^{\circ} \mathrm{C}$, and then for $3 \mathrm{~h}$ at $37^{\circ} \mathrm{C}$. Plasminogen activator activity was visualised as lysis zones in the underlying plasminogen/ substrate gel and documented using Bio-Rad Imager (ChemiDoc ${ }^{\text {TM }}$ XRS; Bio-Rad Laboratories Inc., Hercules, CA, USA).

\section{Statistics}

Data are given as mean $\pm \mathrm{SD}$. For statistical analysis of differences among groups, nonparametric tests were employed (Kruskal-Wallis H-test followed by Mann-Whitney U-test). Levels of significance are indicated. A p-value $<0.05$ was considered statistically significant.

\section{RESULTS}

The early period after bleomycin challenge was characterised by an acute inflammatory reaction in the lung with a pronounced influx of polymorphonuclear neutrophils and a marked plasma protein leakage into the alveolar compartment. The later course was characterised by a fibroproliferative response with reduced pulmonary compliance at day 28 after bleomycin treatment (table 1). Histological examination revealed extensive fibrosis (not shown).

Following bleomycin challenge, a significant upregulation of TF mRNA expression was observed in BALF and microdissected AM during the acute inflammatory phase (day 4; 250- and 200-fold induction, respectively), which was even more pronounced during the late fibroproliferative period (270- and 250-fold induction, respectively; fig. 1a). To a lesser extent, an increase of TF mRNA expression was also observed in ATII (30-fold induction at day 4 and 40-fold induction at day 28; fig. 1a). Western blot analysis detected a marked increase of TF protein after bleomycin challenge in the lung homogenate, in BALF AM as well as in the cell-depleted BALF supernatant, indicating shedding of TF (fig. 1b). Immunohistochemical studies detected TF in AM (Fig. 1c) and in hyperplastic ATII (fig. 1d) 4 (not shown) and 28 days after bleomycin challenge, as compared with sham-treated control lungs, in which a slight positive signal for TF was detected in AM only (fig. 1e).

At day 4 after bleomycin challenge, PAI-1 mRNA expression was upregulated 25- and 60-fold in BALF and microdissected $\mathrm{AM}$, respectively, and to a lesser extent in ATII cells (eight-fold induction). The increase of PAI-1 mRNA expression in these cells was slightly more pronounced during the fibroproliferative period (fig. 2a). Accordingly, an increase of PAI-1 protein was detected in BALF macrophages, in the cell-depleted BALF supernatant and in the lung homogenate (fig. 2b). AM (fig. 2c) and, to a lesser extent, hyperplastic ATII cells (fig. 2d) stained positive for PAI-1 at days 4 (not shown) and 28 after bleomycin challenge. In contrast, in sham-treated control lungs only AM stained slightly positive (fig. 2e).

\begin{tabular}{|c|c|c|c|c|}
\hline \multirow[t]{3}{*}{ TABLE 1} & \multicolumn{4}{|c|}{$\begin{array}{l}\text { Bronchoalveolar lavage fluid (BALF) protein } \\
\text { concentration, cell differential and pulmonary } \\
\text { compliance after inhalational bleomycin } \\
\text { challenge }\end{array}$} \\
\hline & \multicolumn{2}{|c|}{ Bleomycin } & \multicolumn{2}{|c|}{ Control } \\
\hline & Day 4 & Day 28 & Day 4 & Day 28 \\
\hline Protein $\mu \mathrm{g} \cdot \mathrm{mL}^{-1}$ & $959.2 \pm 125.2$ & $492.0 \pm 99.1$ & $200.7 \pm 53.8$ & $214.5 \pm 97.5$ \\
\hline AM \% & $63.0 \pm 2.0$ & $90.1 \pm 1.0$ & $97.0 \pm 2.3$ & $95.2 \pm 5.3$ \\
\hline PMN \% & $37.0 \pm 0.8$ & $9.9 \pm 2.9$ & $3.0 \pm 5.0$ & $4.8 \pm 2.1$ \\
\hline $\begin{array}{l}\text { Compliance } \\
\mathrm{mM} \cdot \mathrm{kPa}^{-1} \cdot \mathrm{kg}^{-1}\end{array}$ & & $2.1 \pm 0.4$ & & $4.7 \pm 0.4$ \\
\hline \multicolumn{5}{|c|}{$\begin{array}{l}\text { Data are shown as mean } \pm \text { SD from } 10 \text { mice for each group. BALF protein } \\
\text { concentration, BALF cell differential and pulmonary compliance for sham- } \\
\text { treated mice (control) and for bleomycin-challenged mice at days } 4 \text { and } 28 \text { after } \\
\text { inhalational administration of } 15 \mathrm{mg} \cdot \mathrm{kg}^{-1} \text { bleomycin are given. AM: alveolar } \\
\text { macrophages; PMN: polymorphonuclear neutrophils. }\end{array}$} \\
\hline
\end{tabular}


a)

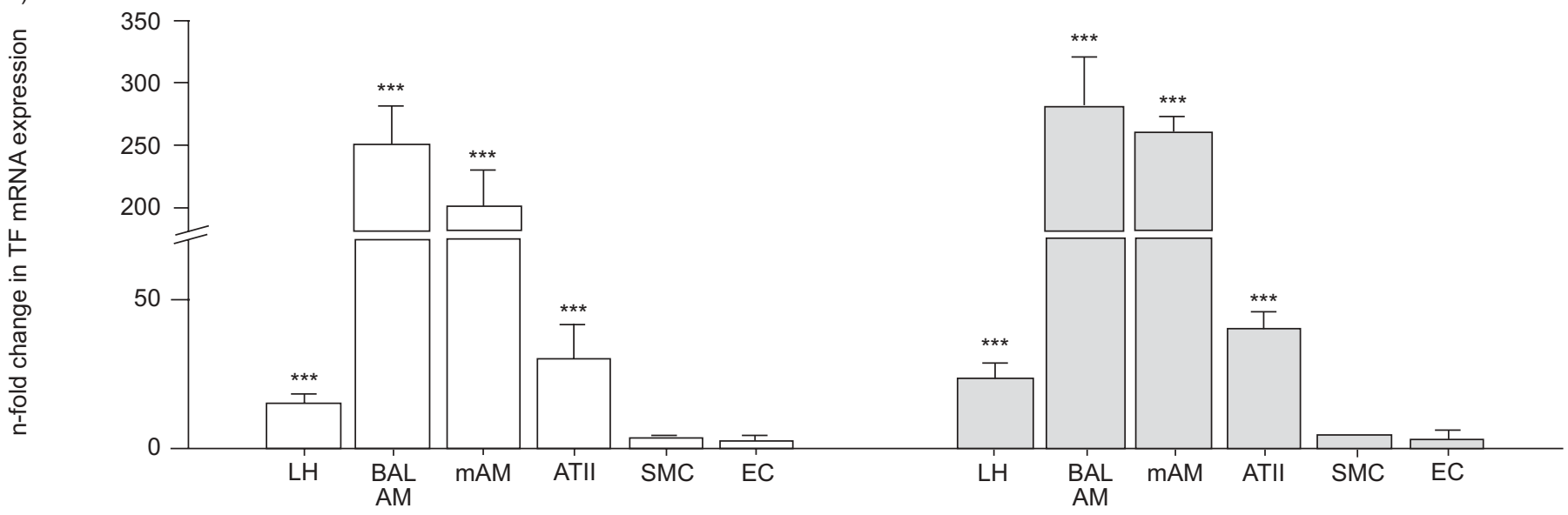

b)
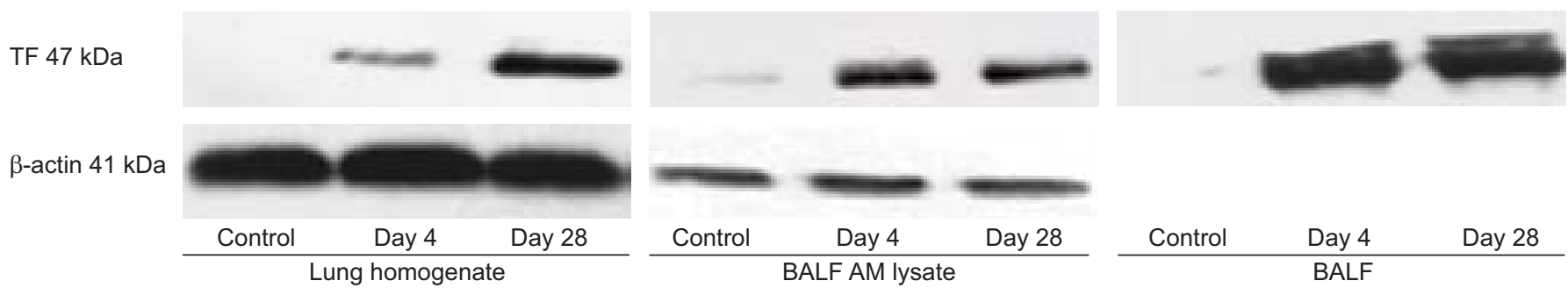

$\beta$-actin $41 \mathrm{kDa}$
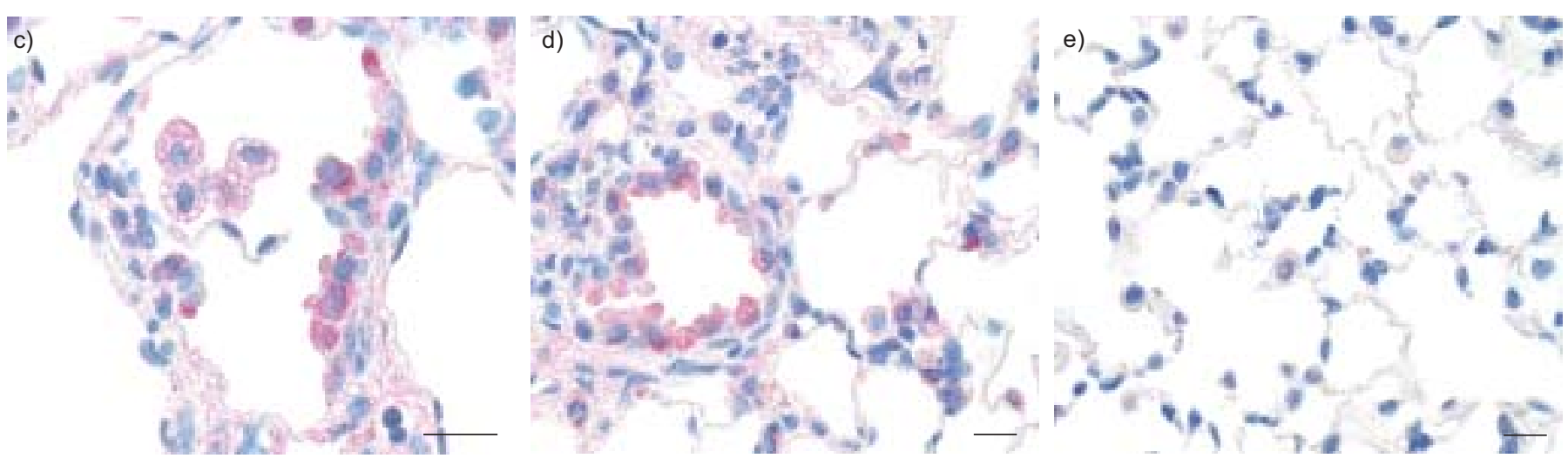

FIGURE 1. Tissue factor (TF) expression in the murine lung after inhalational bleomycin challenge. a) TF mRNA expression in different lung cells 4 ( $\square$ ) and 28 days ( $\square$ ) after inhalational bleomycin challenge. The n-fold induction of TF-specific mRNA in different lung cells after inhalational bleomycin challenge is given normalised to values from sham-treated control lungs (set at 1; data presented as mean $\pm \mathrm{SD} ; \mathrm{n}=10$ ). LH: lung homogenate; BAL: bronchoalveolar lavage; AM: alveolar macrophage; mAM: AM obtained by microdissection; ATII: type II alveolar epithelial cells; SMC: smooth muscle cells of medium-size pulmonary vessels; EC: endothelial cells of medium-size pulmonary vessels. ${ }^{* *}: \mathrm{p}<0.001$. b) TF protein expression in the murine lung after inhalational bleomycin challenge. Western blotting was performed on the lung homogenate, the BAL fluid (BALF) AM cell lysate, and the cell-depleted BALF supernatant in sham-treated control lungs 4 and 28 days after bleomycin challenge. Representative blots from five independent experiments are shown. c) Localisation of TF protein in lung tissue. Paraffin-embedded lung sections from sham-treated control mice and from bleomycin-challenged mice (day 28) were stained immunohistochemically with a rabbit anti-TF antibody. Alveolar macrophages (c) as well as hyperplastic ATII (c and d) stained positive for TF in the lungs of bleomycin-treated mice, as compared with sham-treated control lungs, in which a slight positive signal for TF was detected in alveolar macrophages only (e). Representative microscopic fields of view are shown. Five bleomycin-treated and four sham-treated mice were examined. Ten fields were analysed per section for five sections of each mouse. Controls were performed by substituting the primary antibody for a nonspecific antibody (not shown). Scale bars $=5 \mu \mathrm{m}$.

Upregulation of PAI-2 mRNA expression was observed exclusively in microdissected and BALF macrophages, predominantly during the acute inflammatory period (10and 20-fold induction, respectively; fig. 3a). Accordingly, PAI-
2 protein expression in BALF macrophages was higher in the early period after bleomycin challenge as compared with the late fibroproliferative period (fig. $3 b$ ). Strong PAI-2 immunoreactivity was evident in AM at day 4 after bleomycin 


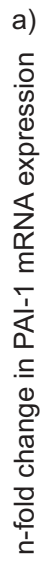

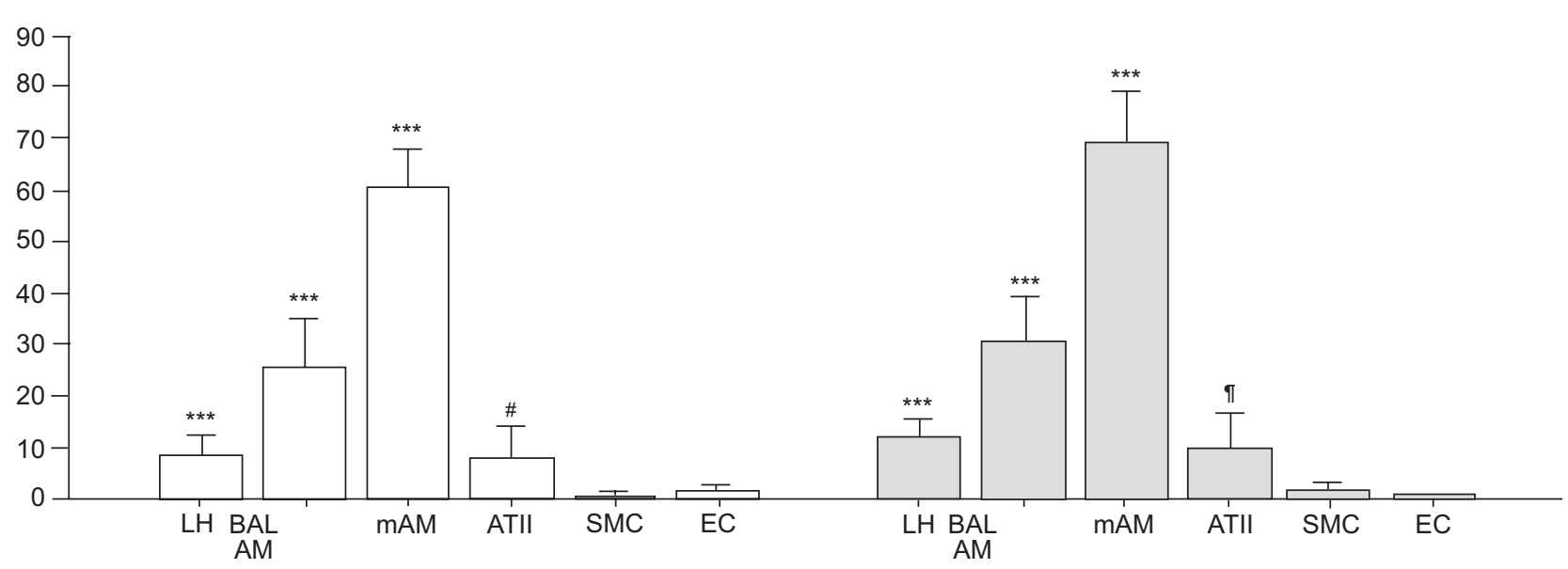

b)
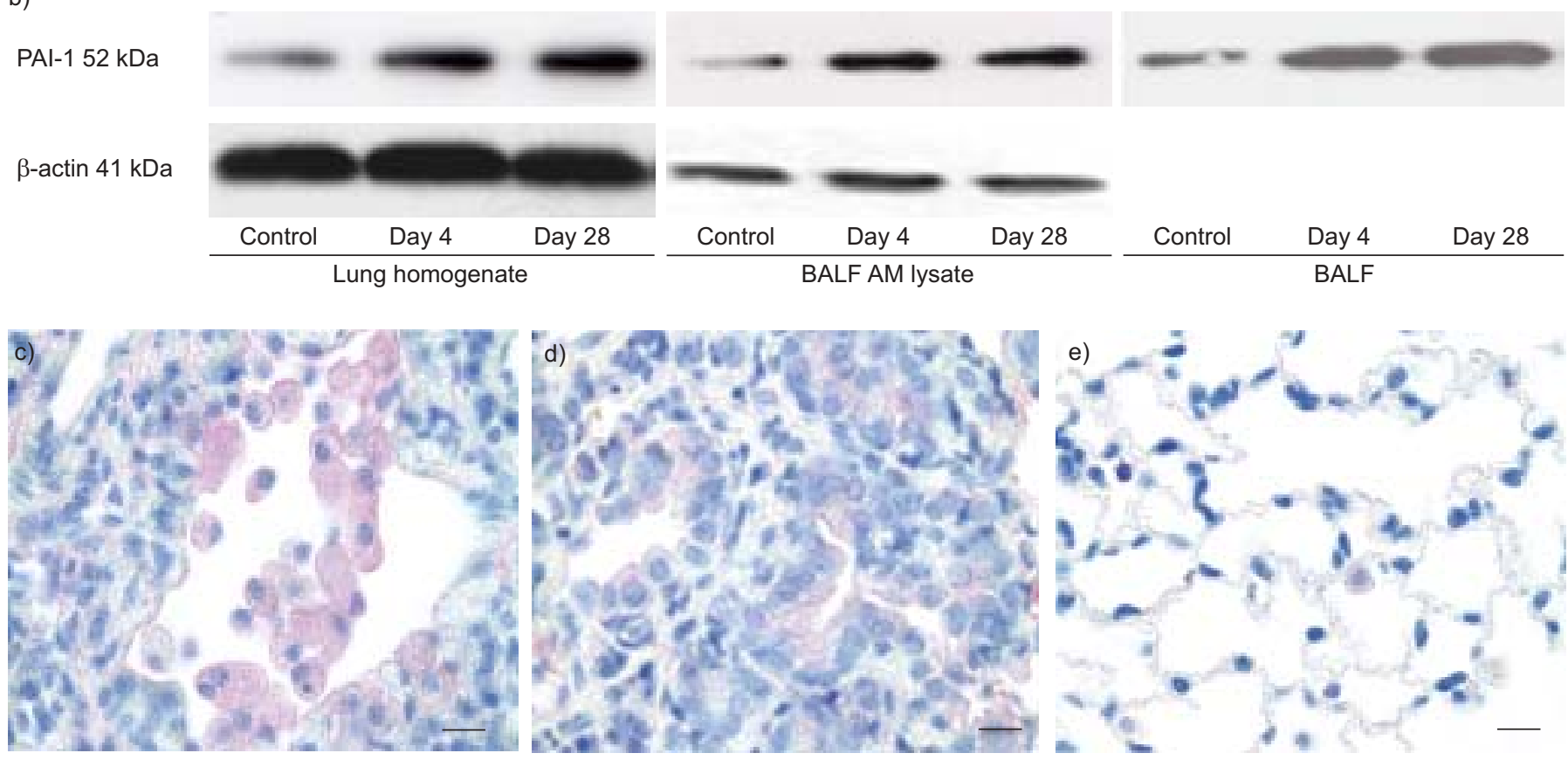

FIGURE 2. Plasminogen activator inhibitor (PAl)-1 expression in the murine lung after inhalational bleomycin challenge. a) PAl-1 mRNA expression in different lung cells $4(\square)$ and 28 days $(\square)$ after inhalational bleomycin challenge. The n-fold induction of PAl-1-specific mRNA in different lung cells after inhalational bleomycin challenge is shown normalised to values from sham-treated control lungs (set at 1; mean $\pm \mathrm{SD} ; \mathrm{n}=10$ ). LH: lung homogenate; BAL: bronchoalveolar lavage; AM: alveolar macrophage; mAM: AM obtained by microdissection; ATII: type II alveolar epithelial cells; SMC: smooth muscle cells of medium-size pulmonary vessels; EC: endothelial cells of mediumsize pulmonary vessels. ${ }^{*}$ : $p=0.02 ;{ }^{\circ}: p=0.009 ;{ }^{* *}: p<0.001$. b) PAl-1 protein expression in the murine lung after inhalational bleomycin challenge. Western blotting was performed on the lung homogenate, the BAL fluid (BALF) AM cell lysate, and the cell-depleted BALF supernatant in sham-treated control lungs, 4 and 28 days after bleomycin challenge. Representative blots from five independent experiments are shown. c) Localisation of PAl-1 protein in lung tissue. Paraffin-embedded lung sections from shamtreated control mice and from bleomycin-challenged mice (day 28) were stained immunohistochemically with a rabbit anti-PAl-1 antibody. Alveolar macrophages (c) and, to a lesser extent, hyperplastic alveolar type II cells (d) stained positive for PAI-1 in the lungs of bleomycin-treated mice. In contrast, in sham-treated control lungs only AMs stained slightly positive (e). Representative microscopic fields of view are shown. Five bleomycin-treated and four sham-treated mice were examined. Ten fields were analysed per section for five sections of each mouse. Controls were performed by substituting the primary antibody for a nonspecific antibody (not shown). Scale bars $=5 \mu \mathrm{m}$.

administration (fig. 3c). Only weak PAI-2 immunostaining was observed in AM at day 28 after bleomycin treatment (fig. 3d). In contrast, in the BALF supernatant (i.e. the secreted form of PAI-2) and in the lung homogenate, PAI-2 protein expression was higher at day 28 after bleomycin administration as compared with the early period (fig. $3 b$ ).
At day 28 after bleomycin treatment, uPA expression was slightly but significantly downregulated in SMC of mediumsize vessels, and a two-fold (statistically nonsignificant) upregulation was observed in AM. No change was observed in any other cell type (table 2). However, uPA activity was markedly decreased in the BALF as well as in the lung 


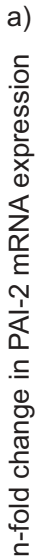

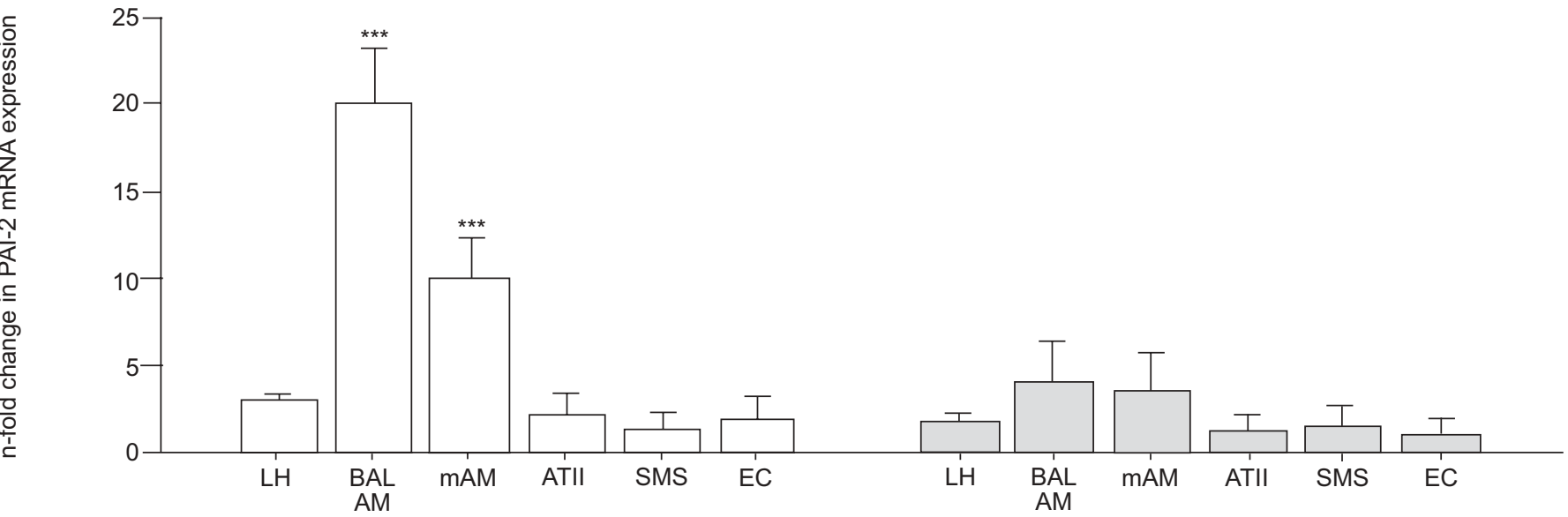

b)

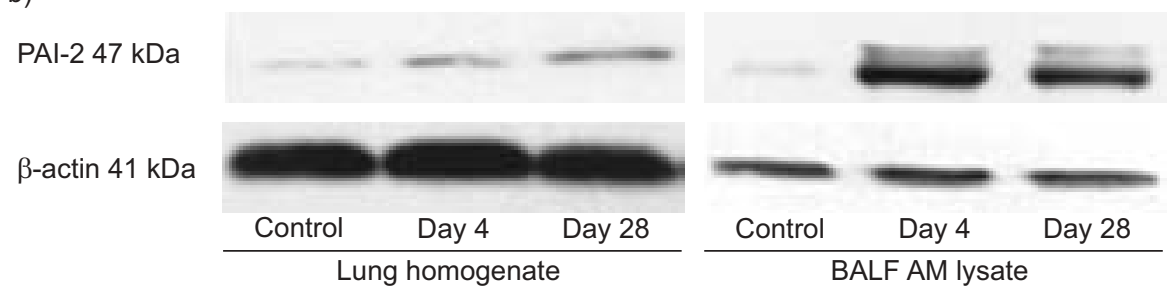

PAI-2

$60 \mathrm{kDa}$

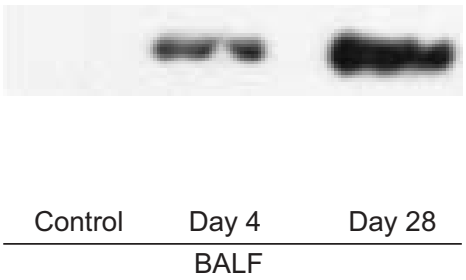

c)
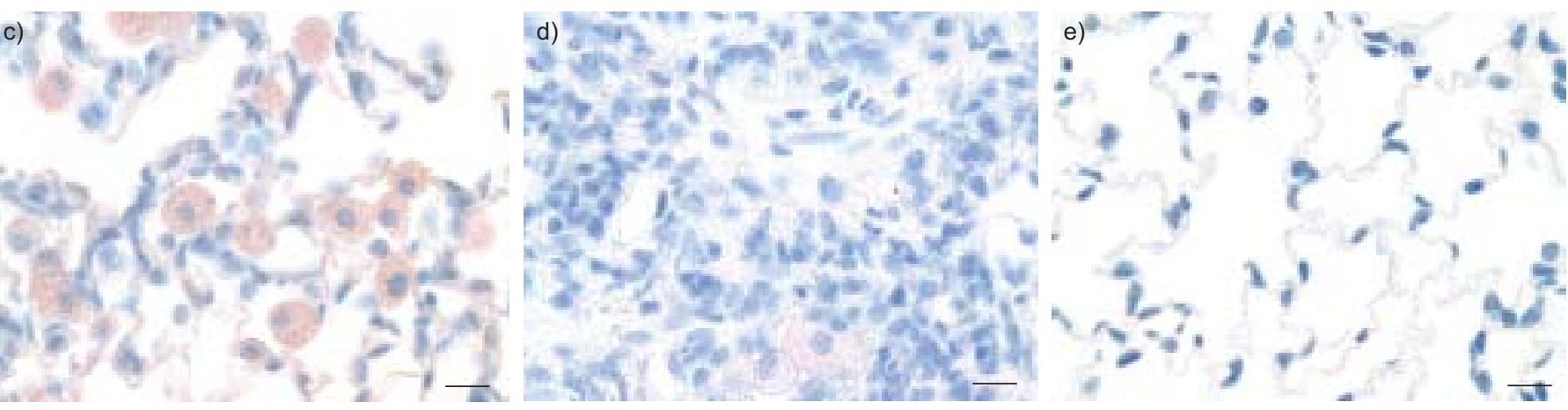

FIGURE 3. Plasminogen activator inhibitor (PAl)-2 expression in the murine lung after inhalational bleomycin challenge. a) PAl-2 mRNA expression in different lung cells $4(\square)$ and 28 days ( $\square$ ) after inhalational bleomycin challenge. Depicted is the $n$-fold induction of PAl-2-specific mRNA in different lung cells after inhalational bleomycin challenge normalised to sham-treated control lungs (set at 1 ; mean $\pm \mathrm{SD} ; \mathrm{n}=10$ ). LH: lung homogenate; BAL: bronchoalveolar lavage; AM: alveolar macrophage; mAM: AM obtained by microdissection; ATII: type II alveolar epithelial cells; SMC: smooth muscle cells of medium-size pulmonary vessels; EC: endothelial cells of medium-size pulmonary vessels. ${ }^{* * *}: \mathrm{p}<0.001$. b) PAl-2 protein expression in the murine lung after inhalational bleomycin challenge. Western blotting was performed on the lung homogenate, the BAL fluid (BALF) AM cell lysate, and the cell-depleted BALF supernatant in sham-treated control lungs, 4 and 28 days after bleomycin challenge. Representative blots out of five independent experiments are shown. c) Localisation of PAl-2 protein in lung tissue. Paraffin-embedded lung sections from sham-treated control mice and from bleomycin-challenged mice were stained immunohistochemically with a goat anti-PAI-2 antibody. Strong PAl-2 immunoreactivity was evident in AMs 4 days after bleomycin administration (c), but not on day 28 after bleomycin administration (d) or in sham-treated control lungs (e). Representative microscopic fields of view are shown. Five bleomycin-treated and four sham-treated mice were examined. Ten fields were analysed per section for five sections of each mouse. Controls were performed by substituting the primary antibody by a nonspecific antibody (not shown). Scale bars $=5 \mu \mathrm{m}$.

homogenate at days 4 and 28 after bleomycin challenge (fig. 4). Higher molecular lysis zones representing uPA-PAI complexes were detected on the zymograms at days 4 and 28 after bleomycin treatment, but not in controls (data not shown).

Expression of TFPI mRNA was not changed in any cell type, except for a slight downregulation in BALF macrophages (table 2). tPA mRNA expression was moderately upregulated in BALF macrophages and more pronounced in EC, particularly on day 28 after bleomycin administration (table 2).

\section{DISCUSSION}

In the present study, the contribution of different resident lung cells to the local abnormalities of coagulation and fibrinolysis 


\begin{tabular}{|c|c|c|c|c|c|c|}
\hline \multirow[t]{3}{*}{ TABLE 2} & \multicolumn{6}{|c|}{$\begin{array}{l}\text { mRNA expression of urokinase-type and tissue-type plasminogen activators (UPA and tPA, respectively) and tissue } \\
\text { factor pathway inhibitor (TFPI) in different lung cells after inhalational bleomycin challenge }\end{array}$} \\
\hline & & UPA & \multicolumn{2}{|c|}{ tPA } & \multicolumn{2}{|c|}{ TFPI } \\
\hline & Day 4 & Day 28 & Day 4 & Day 28 & Day 4 & Day 28 \\
\hline LH & $1.487 \pm 0.570$ & $1.404 \pm 0.199$ & $1.734 \pm 0.843$ & $3.495 \pm 1.495$ & $1.057 \pm 0.243$ & $2.219 \pm 1.087$ \\
\hline BALF AM & $1.276 \pm 0.347$ & $2.045 \pm 0.398$ & $4.732 \pm 2.437$ & $5.264 \pm 2.355^{\#}$ & $0.242 \pm 0.114^{\circ}$ & $0.377 \pm 0.187^{\circ}$ \\
\hline mAM & $0.789 \pm 0.236$ & $2.236 \pm 0.987$ & $0.978 \pm 0.987$ & $0.879 \pm 0.699$ & $1.269 \pm 0.987$ & $1.523 \pm 0.489$ \\
\hline SMC & $1.256 \pm 0.897$ & $0.229 \pm 0.189^{\circ}$ & $0.311 \pm 0.119$ & $1.143 \pm 1.028$ & $0.763 \pm 0.259$ & $0.622 \pm 0.437$ \\
\hline ATII & $0.806 \pm 0.125$ & $0.796 \pm 0.423$ & $0.830 \pm 0.108$ & $1.475 \pm 0.236$ & $1.859 \pm 0.989$ & $2.642 \pm 0.330$ \\
\hline EC & $1.549 \pm 1.239$ & $1.459 \pm 1.001$ & $7.218 \pm 5.981^{\#}$ & $83.351 \pm 58.465^{+}$ & $1.986 \pm 0.983$ & $1.215 \pm 0.741$ \\
\hline
\end{tabular}

in the alveolar space of bleomycin-injured lungs was determined by quantitative mRNA analysis of different procoagulant and (anti)-fibrinolytic factors in these cells. The factors that are thought to play a critical role in the shift of the alveolar haemostatic and fibrinolytic balances in lung injury, namely TF and PAI-1, showed the strongest induction of mRNA expression in AM (TF 250-fold induction; PAI-1 60fold induction in microdissected and 25-fold induction in lavaged macrophages). The recent finding that under physiological conditions AM are the main source of TF and PAI-1 expression in the lung ([15] and unpublished observations), combined with the present data, demonstrate that AM are primarily responsible for the local production of these factors in bleomycin-induced lung injury. Interestingly, following bleomycin treatment, microdissected macrophages showed a considerably stronger increase of PAI-1 expression as compared with lavaged macrophages, indicating that these two types of macrophages are phenotypically different. A slight increase of uPA expression (two-fold induction) was also observed in AM, but uPA activity in the lung was reduced due to disproportionate increase of PAI production. Following bleomycin challenge, TF- and PAI-mRNA expression were also upregulated in ATII, which may also, therefore, contribute to local abnormalities of coagulation and fibrinolysis in the alveolar space of bleomycin-injured lungs. However, TF and PAI-1 were induced in the presently studied cell population to an approximately six-fold lesser extent as compared with AM.

The expression of some pro-coagulant and (anti)-fibrinolytic genes during bleomycin-induced lung injury has been previously investigated by in situ hybridisation [4]. In this latter study, PAI-1, uPA and TF mRNAs were localised to the fibrinrich fibroproliferative lesions, primarily to macrophage-like cells (uPA and TF), to fibroblast-like cells (PAI-1) and most likely to ATII (TF) [4]. Expanding on this, the current authors combined laser-assisted microdissection technology and realtime quantitative RT-PCR to analyse mRNA expression in specific cell populations. This method allows sensitive and reliable mRNA quantification, and mRNA contents can be precisely assigned to a specific cell type since the microdissection technique is complemented by a cell-type-specific immunostaining. Cell populations were identified by immunostaining against pro-SP-C (ATII), vWF (EC) and CD68 (AM). Optimal conditions for mRNA amplification from immunodetected cells were recently identified by the current authors' group $[15,22]$, and cell type specificity was confirmed by analysing the mRNA expression of SP-C and vWF in the different cell populations after immunostaining-guided and laser-assisted microdissection (data not shown). The utilised technique still has some limitations. In particular, the current authors were not able to develop technology to sample pulmonary alveolar fibroblasts, and thus to investigate the expression of haemostatic factors in these cells. However, the results from the previously mentioned in situ hybridisation study suggest that the expression of haemostatic factors, particularly PAI-1, may change in fibroblasts in the bleomycininjured lung [4]. Although staining for PAI-1 was not observed in fibroblast-like cells, the current authors cannot rule out some expression of PAI-1 in this cell population. Furthermore, EC were sampled from medium-size vessels but not from capillaries that are too small in size for precise EC microdissection. Capillaries are more readily incorporated into the inflammatory and fibrotic responses than larger vessels. Therefore, EC collected from medium-size vessels may not be exactly representative of capillary EC, and it should be recognised that differences in the content of specific mRNAs may exist between these two EC populations.

The expression of factors of the coagulation and fibrinolysis systems that have until now not been investigated in bleomycin-induced lung injury were also analysed. TFPI is a major physiological inhibitor of the extrinsic coagulation cascade. Interestingly, TFPI was not differentially regulated in bleomycin-injured lungs, in particular no compensatory upregulation of TFPI could be observed in any cell type. This observation adds to the previous hypothesis that TFPI is not capable of limiting the activation of the extrinsic pathway under various pathological circumstances [24]. A significant upregulation of PAI-2 mRNA expression was observed exclusively in microdissected and BALF macrophages (10and 20-fold induction, respectively). PAI-2 is an inhibitor of the extracellular serine protease uPA [25]. Thus, the observed 


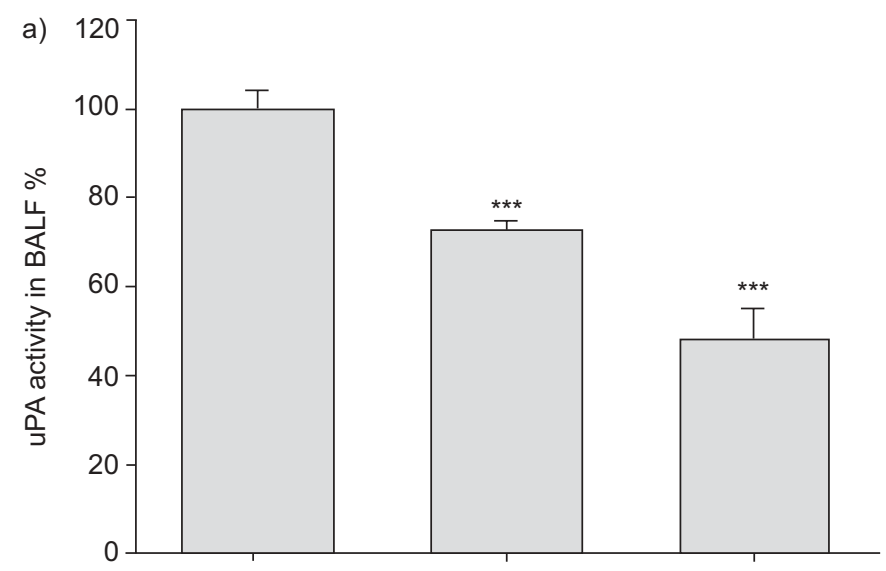

b)

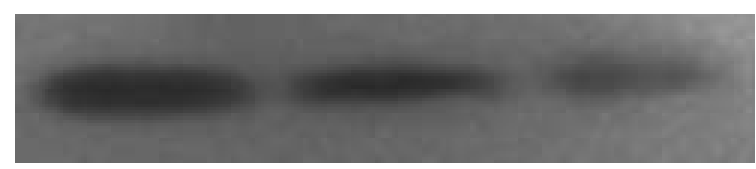

Control

Day 4

Day 28

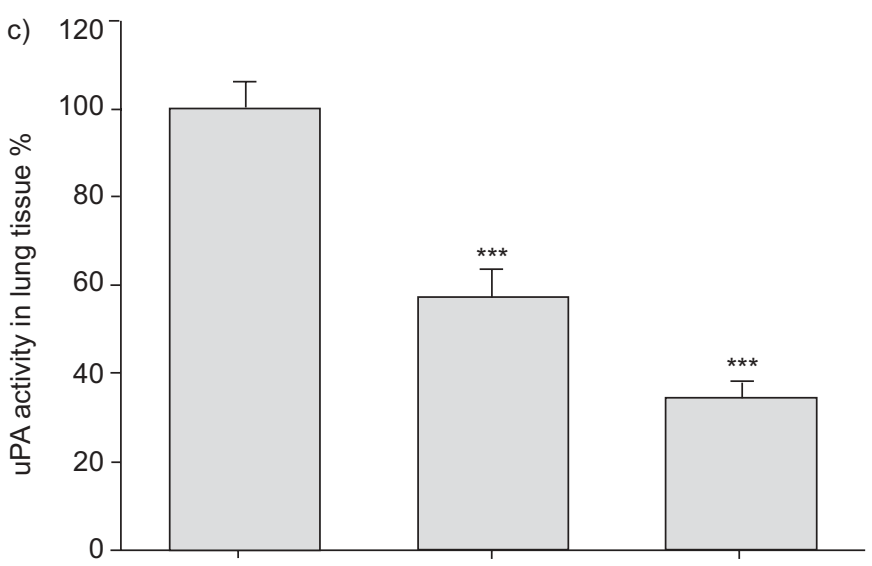

d)

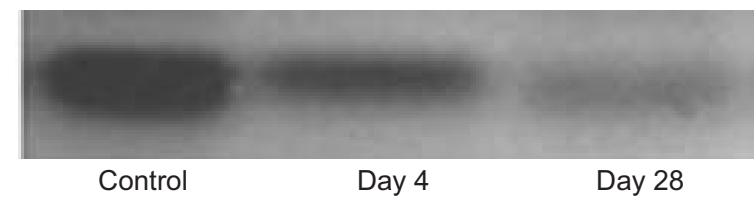

FIGURE 4. Urokinase-type plasminogen activators (UPA) activity in the murine lung after inhalational bleomycin challenge. UPA activity in the a) bronchoalveolar lavage fluid (BALF) and c) lung homogenate of mice 4 and 28 days after inhalational bleomycin challenge is given as a percentage of that in sham-treated mice (control mice: $100 \%$ activity), as assessed by casein zymography. $n=10$ for each group. b) Representative zymogram (one of 10) from BALF. d) Representative zymogram (one of 10) from lung homogenate. ${ }^{* \star}$ : $p<0.001$ for bleomycin-treated versus sham-treated mice.

upregulation of the secreted form of PAI-2 in the BALF after bleomycin challenge may well contribute to the depression of intra-alveolar fibrinolytic activity. However, inhibition of uPA by PAI-2 is less effective by a factor of 10 compared with PAI-1 [25]. Furthermore, most of the de novo synthesised PAI-2 in monocytes/macrophages in response to tumour necrosis factor (TNF)- $\alpha$ remains intracellular, and it has been suggested that the physiological role of PAI-2 in inflammatory macrophages is to protect these cells from the cytotoxic effect of their own
TNF- $\alpha$ [26]. Following bleomycin challenge, the current authors observed a strong upregulation of the intracellular form of PAI-2 in AM during the early exudative phase. Together, these data point to the possibility that PAI-2, in addition to inhibiting extracellular fibrinolysis, also indirectly contributes to the altered alveolar haemostasis in this model by protecting AM from cell death. An upregulation of the intracellular form of PAI-2 was also observed in the lung homogenate, especially at day 28. Since none of the investigated cell types showed a significant upregulation of PAI-2 at this time point, other cells such as fibroblasts could be responsible for this observation.

Next to the factors investigated in the present study, the functional activities of the coagulation and fibrinolysis systems in the distal lung are further determined by unmeasured variables, particularly by cell-surface receptors, such as proteinase-activated receptors (PARs), effector cell protease receptor-1, thrombomodulin and endothelial protein $C$ receptor, which may influence cell signalling as well as procoagulant (i.e. fibrin deposition) effects. Moreover, there is ongoing discussion about the mechanisms by which imbalances in alveolar haemostasis and fibrinolysis may contribute to inflammation and fibrosis in acutely and chronically injured lungs, and especially about the importance of cellular versus pro-coagulant functions of various proteases of the TF-VIIainitiated extrinsic coagulation cascade [1, 27-30]. Excessive extravascular deposition of fibrin may serve as a reservoir of pro-fibrotic growth factors [31] and is thought to inhibit surfactant function and to provide a provisional matrix on which fibroblasts proliferate and produce collagen [8]. A role of fibrin in lung fibrosis is supported by the findings that in mice, lack of PAI-1 results in an attenuated fibroproliferative response to bleomycin challenge, whereas in PAI-1-overexpressing mice the fibroproliferative response is potentiated [28]. However, lung injury and fibrosis still develop in fibrinogen knockout mice after bleomycin treatment [29], suggesting that the cellular rather than the pro-coagulant effects of different proteases of the TF-VIIa-initiated coagulation pathway may play a key role in inflammatory and fibrotic processes following bleomycin challenge. TF-VIIa complexes themselves can activate PARs, including the thrombin-insensitive PAR-2, and upregulate the expression of pro-inflammatory cytokines and growth factors in different cell types [27, 32 , 33]. Factor $X$ a stimulates fibroblast proliferation, pro-collagen production and connective tissue growth factor (CTGF) expression via proteolytic activation of PAR-1, and factor Xainduced expression of pro-inflammatory cytokines in EC was demonstrated to be PAR-2 mediated $[10,13,14]$. These proteases are required at relatively high concentrations for PAR activation, but ternary TF-VIIa-Xa complexes were recently shown to produce enhanced cell signalling compared with the TF-VIIa complex alone or free Xa [34]. Similar pro-inflammatory and pro-fibrotic cellular effects have also been demonstrated for thrombin, mostly mediated via proteolytic activation of PAR-1. Thrombin enhances fibroblast proliferation and induces pro-collagen and CTGF expression in these cells in vitro $[9,10]$. Thrombin can increase the expression of profibrotic cytokines from AM and exerts pro-inflammatory effects, for instance by stimulating the release of chemoattractants and pro-inflammatory cytokines by different cell 
types, which may, in turn, contribute to further production of pro-coagulant and anti-fibrinolytic factors [11, 12, 14]. Additionally, it has been demonstrated that the direct inhibition of thrombin attenuates collagen accumulation in bleomycininjured rat lungs, and that the protective effect is associated with reduced mRNA levels of both pro-collagen and CTGF. These findings give further support to thrombin's cellular effects as an important pathogenetic mechanism in this model [7]. Moreover, the critical role of the major thrombin receptor PAR-1 in pulmonary inflammation and fibrosis is underscored by the recent observation that PAR-1-deficient mice are protected from bleomycin-induced lung injury [30]. Interestingly, increased expression of thrombin and PAR-1 in bleomycin-injured lungs is predominantly localised to AM in inflammatory and fibroproliferative lesions [7]. In these conditions, active thrombin may leak from the vascular into the alveolar compartment. However, the current authors demonstrate a strong increase of TF expression in AM after bleomycin injury, suggesting that thrombin may be locally generated on macrophages in the alveolar space of bleomycin-injured lungs.

In summary, the present study addressed the cell-specific and quantitative expression of pro- and anti-coagulant and (anti)fibrinolytic factors in bleomycin-injured lungs. The most farreaching induction of both tissue factor, the primary cellsurface initiator of the extrinsic coagulation pathway, and plasminogen activator inhibitor-1, the major inhibitor of the fibrinolysis system, were observed in alveolar macrophages. Previous studies have demonstrated that thrombin can be found on the surface of macrophages in lung tissue [35] and can increase the expression of pro-fibrotic cytokines from these cells [12]. These findings, combined with the present data and with the recent observations that elevated thrombin levels and increased expression of proteinase-activated receptor- 1 in the bleomycin-injured lung are mainly associated with alveolar macrophages [7], point to a key role for this cell type in the fibrotic response after bleomycin challenge, in which it may be critically involved in pro-coagulant as well as cellular effects of the alveolar haemostatic system.

\section{ACKNOWLEDGEMENTS}

The authors would like to thank L. Marsh for proofreading the manuscript and G. Mueller (both Giessen, Germany) for excellent technical assistance.

\section{REFERENCES}

1 Idell S. Coagulation, fibrinolysis, and fibrin deposition in acute lung injury. Crit Care Med 2003; 31: Suppl. 4, S213-S220.

2 Kotani I, Sato A, Hayakawa H, Urano T, Takada Y, Takada A. Increased procoagulant and antifibrinolytic activities in the lungs with idiopathic pulmonary fibrosis. Thromb Res 1995; 77: 493-504.

3 Idell S, James KK, Gillies C, Fair DS, Thrall RS. Abnormalities of pathways of fibrin turnover in lung lavage of rats with oleic acid and bleomycin-induced lung injury support alveolar fibrin deposition. Am J Pathol 1989; 135: 387-399.

4 Olman MA, Mackman N, Gladson CL, Moser KM, Loskutoff DJ. Changes in procoagulant and fibrinolytic gene expression during bleomycin-induced lung injury in the mouse. J Clin Invest 1995; 96: 1621-1630.

5 Rao LV, Rapaport SI. Activation of factor VII bound to tissue factor: a key early step in the tissue factor pathway of blood coagulation. Proc Natl Acad Sci USA 1988; 85: 6687-6691.

6 Hernandez-Rodriguez NA, Cambrey AD, Harrison NK, et al. Role of thrombin in pulmonary fibrosis. Lancet 1995; 346: 1071-1073.

7 Howell DC, Goldsack NR, Marshall RP, et al. Direct thrombin inhibition reduces lung collagen, accumulation, and connective tissue growth factor mRNA levels in bleomycin-induced pulmonary fibrosis. Am J Pathol 2001; 159: 1383-1395.

$8 \mathrm{McDonald}$ JA. The yin and yang of fibrin in the airways. N Engl J Med 1992; 13: 929-931.

9 Chambers RC, Dabbagh K, McAnulty RJ, Gray AJ, BlancBrude OP, Laurent GJ. Thrombin stimulates fibroblast procollagen production via proteolytic activation of protease-activated receptor 1. Biochem J 1998; 333: 121-127.

10 Chambers R, Leoni P, Blanc-Brude O, Wembridge D, Laurent GJ. Thrombin is a potent inducer of connective tissue growth factor production via proteolytic activation of protease-activated receptor-1. J Biol Chem 2000; 275: 35584-35591.

11 Ueno A, Murakami K, Yamanouchi K, Watanabe M, Kondo T. Thrombin stimulates production of interleukin-8 in human umbilical vein endothelial cells. Immunology 1996; 88: 76-81.

12 Tani K, Ogushi F, Takahashi H, Kawano T, Endo T, Sone S. Thrombin stimulates platelet-derived growth factor release by alveolar macrophages - significance in bleomycininduced pulmonary fibrosis. J Med Invest 1997; 44: 59-65.

13 Blanc-Brude OP, Archer F, Leoni P, et al. Factor Xa stimulates fibroblast procollagen production, proliferation, and calcium signaling via PAR1 activation. Exp Cell Res 2005; 304: 16-27.

14 Shimizu T, Nishihira J, Watanabe $\mathrm{H}$, et al. Macrophage migration inhibitory factor is induced by thrombin and factor Xa in endothelial cells. J Biol Chem 2004; 279: 13729-13737.

15 Wygrecka M, Markart P, Ruppert C, et al. Compartmentand cell-specific expression of coagulation and fibrinolysis factors in the murine lung undergoing inhalational versus intravenous endotoxin application. Thromb Haemost 2004; 92: 529-540.

16 McGee MP, Wallin R, Wheeler FB, Rothberger H. Initiation of the extrinsic pathway of coagulation by human and rabbit alveolar macrophages: a kinetic study. Blood 1989; 74: 1583-1590.

17 Chapman HA, Yang XL, Sailor LZ, Sugarbaker DJ. Developmental expression of plasminogen activator inhibitor type 1 by human alveolar macrophages. Possible role in lung injury. J Immunol 1990; 145: 3398-3405.

18 Gross TJ, Simon RH, Sitrin RG. Tissue factor procoagulant expression by rat alveolar epithelial cells. Am J Respir Cell Mol Biol 1992; 6: 397-403.

19 Erlich J, Fearns C, Mathison J, Ulevitch RJ, Mackman N. Lipopolysaccharide induction of tissue factor expression in rabbits. Infect Immunol 1999; 67: 2540-2546.

20 Idell S, Zwieb C, Boggaram J, Holiday D, Johnson AR, Raghu G. Mechanisms of fibrin formation and lysis by 
human lung fibroblasts: influence of TGF-beta and TNFalpha. Am J Physiol 1992; 263: L487-L494.

21 Moldow CF, Bach RR, Staskus K, Rick PD. Induction of endothelial tissue factor by endotoxin and its precursors. Thromb Haemost 1993; 70: 702-706.

22 Fink L, Kinfe T, Seeger W, Ermert L, Kummer W, Bohle RM. Immunostaining for cell picking and real-time mRNA quantitation. Am J Pathol 2000; 157: 1459-1466.

23 Chomczynski P, Sacchi N. Single-step method of RNA isolation by acid guanidinium thiocyanate-phenol-chloroform extraction. Anal Biochem 1987; 162: 156-159.

24 Shimokawa T, Yamamoto K, Kojima T, Saito H. Downregulation of murine tissue factor pathway inhibitor mRNA by endotoxin and tumor necrosis factor- $\alpha$ in vitro and in vivo. Thromb Res 2000; 100: 211-221.

25 Thorsen S, Philips M, Selmer J, Lecander I, Astedt B. Kinetics of inhibition of tissue-type and urokinase-type plasminogen activator by plasminogen-activator inhibitor type 1 and type 2. Eur J Biochem 1988; 175: 33-39.

26 Dickinson JL, Bates EJ, Ferrante A, Antalis TM. Plasminogen activator inhibitor type 2 inhibits tumor necrosis factor- $\alpha$ induced apoptosis: evidence for an alternate biological function. J Biol Chem 1995; 270: 27894-27904.

27 Ruf W, Riewald M. Tissue factor-dependent coagulation protease signaling in acute lung injury. Crit Care Med 2003; 31: Suppl. 4, S231-S237.

28 Eitzman DT, McCoy RD, Zheng X, Fay PF, Shen T, Ginsburg D. Bleomycin-induced pulmonary fibrosis in transgenic mice that either lack or overexpress the murine plasminogen activator inhibitor-1 gene. J Clin Invest 1996; 97: 232-237.

29 Hattori N, Degen JL, Sisson TH, et al. Bleomycin-induced pulmonary fibrosis in fibrinogen-null mice. J Clin Invest 2000; 106: 1341-1350.

30 Howell DC, Johns RH, Lasky JA, et al. Absence of proteinase-activated receptor-1 signaling affords protection from bleomycin-induced lung inflammation and fibrosis. Am J Pathol 2005; 166: 1353-1365.

31 Grainger DJ, Wakefield L, Bethell HW, Farndale RW, Metcalfe JC. Release and activation of platelet latent TGF- $\beta$ in blood clots during dissolution with plasmin. Nat Med 1995; 1: 932-937.

32 Hjortoe GM, Petersen LC, Albrektsen T, et al. Tissue factorfactor VIIa-specific up-regulation of IL-8 expression in MDA-MB-231 cells is mediated by PAR-2 and results in increased cell migration. Blood 2004; 103: 3029-3037.

33 Pendurthi UR, Allen KE, Ezban M, Rao LV. Factor VIIa and thrombin induce the expression of Cyr61 and connective tissue growth factor, extracellular matrix signaling proteins that could act as possible downstream mediators in factor VIIa $\mathrm{x}$ tissue factor-induced signal transduction. J Biol Chem 2000; 275: 14632-14641.

34 Riewald M, Ruf W. Mechanistic coupling of protease signaling and initiation of coagulation by tissue factor. Proc Natl Acad Sci USA 2001; 98: 7742-7747.

35 Zacharski LR, Memoli VA, Morain WD, Schlaeppi JM, Rousseau SM. Cellular localization of enzymatically active thrombin in intact human tissues by hirudin binding. Thromb Haemost 1995; 73: 793-797. 